\title{
Chinese Perspectives on Medical Missionaries in the 19th Century: The Chinese Medical Missionary Journal
}

\author{
GAO Xi*
}

\section{Introduction}

The China Medical Missionary Journal (CMMJ) was an English-language academic medical journal first published in 1887 by the Medical Missionary Association of China (MMAC). It was intended for medical missionary colleagues working in China. Later it reported on events sponsored by the Association and other information, published papers on the members' experiences in medicine, their investigations of local diseases, and information on updates in Western medical science. It also published studies on traditional Chinese medicine, which it recognized, and on how to stay healthy. Moreover, while the China Medical Missionary Journal kept up-to-date on trends in medical missionary developments, it also carried special items on severe problems in the medical mission on an irregular basis. The China Medical Missionary Journal changed its name to the China Medical Journal (CMJ) in 1907. In 1932, the Medical Missionary Association of China (MMAC) and the National Medical Association of China (NMAC) merged. When the merger took place, the China Medical Journal and the National Medical Journal of China (NMJA) also combined and was later renamed The Chinese Medical Journal, which has English and Chinese versions. The English version of The Chinese Medical Journal, based on the China Medical Missionary Journal and Chinese Medical Journal, is so far the only academic periodical that has lasted for over two centuries and is published both at home and abroad.

In March 1887, the China Medical Missionary Journal was first published in Shanghai after revision of the name and the original plan of the journal. That is, the prefix "China" was added to the name, Missionary Medical Journal. There was no official Chinese name for the journal in the begin-

* History Department, Fudan University 
ning. ${ }^{1}$ According to a paper published by the Zhongguo xingyichuan jiaohuiqi 中国行医传教会启 (Announcement of the Medical Missionary Association of China), in the first issue, the Chinese name of the journal was Xingyi gongbao 行医公报, while papers from the Yidao kefu chuandao shuo 医道可辅 传道说 (Essays on Medical Missions) were known as "Yixue xinbao" 医学新 报 in the same issue. ${ }^{2}$ However, neither was seen on the cover of the Journal, which was still an unofficial publication. It was not until twenty years later that the official name made its first appearance. The Association held a National Conference in April, 1907 at which the matter of a Chinese name for the Association and the Journal was discussed and submitted to the Terminology Committee (TC), which had been established in 1890 by the Medical Missionary Association. It did not prove an easy matter to decide, and the several names submitted by various members of the Association were most courteously "chewed up" by the more select council with an eventually satisfactory result. Dr. P. B. Cousland (1860-1930), the head of the Terminology Committee, wrote to the Association: "After a lot of discussion and consultation we have decided to recommend the Chinese name, Boyi huibao 博医会报." 3 The English and Chinese names were both imprinted on the cover from the fourth issue published in 1907.

A "Chinese perspective" is usually defined as observations of the world by a "Chinese person," or emphasis on the perspectives and attitudes of the Chinese people. In the China Medical Missionary Journal, however, the "Chinese perspective" had a whole different meaning because the Journal was established and written by Western doctors and medical missionaries and read by Westerners. Thus, essentially, the periodical can be regarded as "viewing the Chinese culture of medicine, the Chinese patient, and Chinese society from foreign perspectives." The methodology used by the Journal was empirical. The Association's main aim in this periodical can be understood by considering two aspects: study of the culture of Chinese medicine and the endeavor to promote medical science locally by holding discussions and making plans for execution of policy. In order to accomplish the latter, several questions were waiting to be answered: first of all, as Chinese students needed medical training and education, should they be trained and taught in English or in Chinese? ${ }^{4}$ This was one of the most hotly debated

1 The name of said periodical was to be the Missionary Medical Journal: The Chinese Recorder, 1887; 18(1): 33-34.

2 CMMJ, 1887; 1(1): 43-44.

3 "Our Chinese Name, The China Medical Journal" (CMJ), 26(4): 221.

4 Editorial, "The Chinese Language as a Medium of Scientific Instruction," CMMJ, 1888; 2(1): 28-29. 
matters in the history of the Association. The China Medical Missionary Journal recorded and witnessed the development of Chinese medical education from the stages of prototype and growth to eventual maturation.

The second problem that had to be solved was the determination of medical terminology. This was a major concern in regards to the matter of localization of Western medicine. Members of the Terminology Committee were all capable of reading the masterpieces of traditional Chinese medicine and were equipped with a good knowledge of the medical field. The China Medical Missionary Journal was witness to the entire process of medical missionaries striving to decipher the masterpieces of traditional Chinese medicine from a Western medical perspective during the late nineteenth to the early twentieth centuries. In the face of different viewpoints and opinions, the Terminology Committee achieved agreement on the setting of standards for terminology through conciliation, establishment of protocols, and resolution of disagreements. For instance, “cleft lip and palate" was translated as 缺唇 instead of 崩 口, and cataract as 睛珠生膜 instead of 睛珠变质. ${ }^{5}$ This was a first major step in the course of localization of Western medicine.

The third issue, the status of Chinese interpretation of Western medical books and the progress of publication of Chinese medical textbooks, was reported by the publishing committee. ${ }^{6}$

Scholars both in China and abroad have made tremendous strides in research on the second problem mentioned above, that is, on thematic studies of the "medical mission," medical terminology, medical education and textbooks, public health, and even gynecology by using the China Medical Missionary Journal as a primary source. Using the China Medical Missionary Journal also as my own chief source, I will discuss one of the most easily overlooked but common themes: the Chinese perspective. In fact, as I just mentioned, the Chinese perspective of the China Medical Missionary Journal was evident from the time the Journal came into existence. It was represented by the Association's attitudes towards traditional Chinese medicine and its culture, as well as the Association's plan for and attitudes toward the development of Chinese modern medicine. The "Chinese perspective" itself had a certain direction of development temporally and spatially. It was always transforming noticeably or in silence. Either way, its changes in form, along with development of the internal structure of the Association and external factors such as the structure of Chinese society, ultimately affected the

5 E-Shing, "A Vocabulary of Disease in English and Chinese," CMMJ, 1887, 1(2): 80-82.

6 B. C. Atterbury, "The Translations of Medical Books into Chinese," CMMJ, 188, 2(1): 1-3. 
survival and development of the Association and the China Medical Missionary Journal.

\section{A Chinese Medical Journal Planned}

At first, H. W. Boone (1839-1925), one of the founders of the Association, meant to create a Chinese version of the medical journal on grounds that the medical missionaries "not forget that we are working for the Chinese." $\mathrm{He}$ emphasized the idea, "let us have a copy of the quarterly Journal printed in Chinese in a Chinese paper and send it to every Chinese medical graduate, every medical student or assistant, of any foreign medical worker, and let us urge them to write for this Chinese periodical and give their own views and experiences." ${ }^{7}$ When the China Medical Missionary Journal was established, a universally agreed principle by the council members was that they were creating an English journal with one or two Chinese medical theses in cases where references were needed. ${ }^{8}$

There were two Chinese articles in the first issue in 1887, but none appeared after that. In 1888, John Glasgow Kerr (1824-1901) and Henry T. Whitney proposed that they publish a medical quarterly in Chinese. The latter also recommended $\mathrm{H}$. W. Boone to be the editor. ${ }^{9} \mathrm{H}$. W. Boone replied that the establishment of a good medical journal in Chinese was a most necessary and important undertaking, especially for those interested in China as a whole and Western medical science. "It is the general opinion that such a journal is needed." However, H. W. Boone refused the job because his already busy schedule did not allow it. In the meantime, he contended that only people who knew both Chinese and medical knowledge would be qualified for the job. It seems that Whitney, who at that time was working on translation of an anatomy textbook, was the best candidate. ${ }^{10}$ The Chinese version of the Journal would have to wait a while before being published.

Circumstances changed in 1889 when the chief editor of the Chinese Scientific and Industrial Magazine, John Fryer (1839-1928), sent a letter to the Association, asking that they offer him some of their Chinese medical articles. ${ }^{11}$ The Chinese Scientific and Industrial Magazine was a Chinese journal in the late Qing dynasty that was designed to propagate scientific technology. Judging from the characteristics of the journal, Chinese Scientific

7 H. W. Boone, The Chinese Recorder, 1886, 17(10): 400.

8 中国行医传教会启, $C M M J, 1887,1(1): 41$.

9 J. G. Kerr, "Moderate Drinking as a Chinese of Disease," CMMJ, 1888; 2(2): 47-51; H. T. Whitney," A Medical Quarterly in Chinese," CMMJ, 1888; 2(2): 59.

10 H. W. Boone, “A Chinese Medical Journal," CMMJ, 1888; 2(3): 114-115.

11 "Notes and Items," CMMJ, 1889; 3(4): 178. 
and Industrial Magazine greatly valued knowledge concerning medical science and health. This can be discerned from the fact that the Chinese collaborator, Xu Gaodi 舒高第, contributed six articles about Western medicine. Fryer translated the book, The Chemistry of Common Life 化学卫生论, which is acknowledged to be the earliest work containing a Chinese term for hygiene. It was published in 24 issues continuously in the Chinese Scientific and Industrial Magazine from 1878 through 1882. Fryer's interest in medical knowledge is obvious not only from the fact that he translated and edited medical articles, but also in that he personally bonded with medical missionaries. Fryer wished to cooperate with the Association, offering their members a partial layout in his journal. ${ }^{12}$ As it turned out, the Association regarded his offer a great opportunity: before they established an official Chinese version of the journal, they could use the Chinese Scientific and Industrial Magazine's layout as a temporary substitute. ${ }^{13}$ In 1890 Dr. Kerr and Dr. Whitney recommended Fryer as an honorary member of the Association in light of his achievements in the medical field and encouraged members of the Association to contribute their papers to the Chinese Scientific and Industrial Magazine. ${ }^{14}$ In 1891 when H. W. Boone was no longer president of the Association, in his farewell speech he mentioned several times cooperation with the Chinese Scientific and Industrial Magazine, stating that he supported Fryer. ${ }^{15}$

In order to recommend the Chinese Scientific and Industrial Magazine to members, the China Medical Missionary Journal also included the Chinese Scientific and Industrial Magazine's name and a brief introduction of its contents in the publication. Moreover, they also mentioned that they took note of sanitary science 居宅卫生论, Western materia medica 泰西本草撮要, and the sphygmograph 脉表诊病论, which would prove of interest to medical men. ${ }^{16}$ In 1891 Dr. Kerr provided the medical paper, "Essays on Medicine," translated by Dr. Yin Duanmu 伊端模, to the Chinese Scientific and Industrial Magazine. By then, several papers contributed by members of the Association had been published in the Chinese journal.

The Chinese Scientific and Industrial Magazine cooperated with the China Medical Missionary Journal in several ways, and apparently, Fryer was quite active. The medical achievements of Dr. John Kenneth Mackenzie (1850-

12 S.A.H, "The Chinese Scientific and Industrial Magazine," CMMJ, 1890; 4(3): 217.

13 "Notes and Items," CMMJ, 1889; 3(4): 178.

14 Ibid.

15 H. W. Boone, "Valedictory," CMMJ, 1891; 5(1): 26-27.

16 "The Chinese Scientific and Industrial Magazine," Vol.V. No. 1, CMMJ, 1890; 4(1): 43. 
1888) of the London Missionary Society in Tientsin was reported in the summer issue while the preface of Kerr's new book, The Surgery, was published in the fall issue of 1891. On February 26, 1892, Dr. Duncan Reid, a doctor at St. Luke's Hospital in Shanghai and a member of the Association, gave the lecture, "The Struggle between Mankind and Gems," at a public club. During the lecture, he introduced pioneering medical science in regards to the French scientist Louis Pasteur's new discovery in microbiology, as well as the fundamental concept of microbiology after reviewing the history of microbiological exploration by Western scientists. Fryer thought very highly of the speech; thus, he had it translated and published in the spring issue of the same year. ${ }^{17}$

Unlike Fryer's concerns towards development of new medicine, the Association members placed more value on professional matters in the course of localization of Western medicine. What was the right way to explain materia medica in Chinese? What was the correct terminology? Such questions involved understanding of professional knowledge and the structure of the system. The editor of the China Medical Missionary Journal pointed out that:

From a medical point of view, the paper on Western Materia Medica, giving the botanical sources, physical qualities and medicinal uses of several drugs, is quite interesting, but it is rather diffuse, and makes one wish that instead of translations we could have original articles that are terse, and better adapted to the state of Chinese knowledge. ${ }^{18}$

He thought that a point or two in terminology required correction. For example, the use of sung hsiang lei (松香类) as a generic term for resins was incorrect, hsiang lei (香类) being a more proper term, etc. He stated, “While transliteration as a principle is generally conceded, it requires careful limitation." 19 Thus, he hoped members of the Association could provide new articles to replace the old and unprofessional translations. The China Medical Missionary Journal considered very important the problem of "science and religion" and "science and superstition" that the Chinese Scientific and Industrial Magazine discussed. "These words are profoundly true, that true science and true religion are but the obverse sides of the one shield, and so

17 人与微生物争战论 “The Struggle with Microbes,” Sketch of the Lecture given by Dr. Duncan Reid in Shanghai, The Chinese Scientific and Industrial Magazine, 1891 Spring.

18 The Chinese Scientific and Industrial Magazine, Vol.V. No. II, CMMJ, 1890; 4(3): 217.

19 The Chinese Scientific and Industrial Magazine, Vol.V. No. II, CMMJ, 1890; 4(3): 217. 
hail with joy, every attempt made towards the education of the Chinese nation in the principles of science." 20 The editors of the China Medical Missionary Journal came to believe more and more firmly in scientific teaching and the spread of knowledge of practical arts and industry as the great leveler of superstition. The China Medical Missionary Journal had in total six papers in the Chinese Scientific and Industrial Magazine, the last of which was published in January 1893 when the magazine suspended publication due to Fryer returning to America for the World Exposition.

In September 1896, Dr. P. B. Cousland wrote to the China Medical Missionary Journal stating, "Doubtless many of us have been feeling increasingly the desirability of having a medical missionary Journal in Chinese, for the benefit of our assistants, students, and ex-students." 21 In order to achieve that, he proposed that the Association be asked to establish a Chinese medical missionary journal, and gave some suggestions in regards to such a journal:

1. That it be in easy wen-li.

2. That it be published quarterly, but that as soon as possible, be issued monthly.

3. That there be a general editor, assisted by ten or twenty collaborators, or assistant editors, and that each one be responsible for a certain amount of copy.

4. That members pick different subjects and areas, updates on the latest developments in a selective way. Areas involved: eyes, ears, skin, bacteriology, gynecology, midwifery, surgery, medicine, materia medica, therapeutics, physiology, chemistry, and biology.

5. That new or rarely used terminology should be followed by the English or Latin terms.

6. That until a definite syllabary was adopted for transliterating foreign proper names the transliterations should be followed by the original names in brackets.

Dr. Cousland planned that the journal also carry translated foreign medical journal articles apart from the articles contributed by members of the Association.

As was expected when the China Medical Missionary Journal was

20 The Chinese Scientific and Industrial Magazine, Vol.V. No.II, CMMJ, 1890; 4(3): 217.

21 P. B. Cousland, "A Medical Missionary Journal in Chinese," CMMJ, 1896; 10(4): 281. 
founded, it brought together people with the same goals. He sincerely hoped that this Chinese medical journal could unify medical assistance and interns scattered around the country so that they could communicate, engage in exchanges, and be mutually supportive, which would ultimately help to extend their knowledge and interest in research. He encouraged original and high quality articles from Chinese assistants and students. His proposal was quickly accepted by the Association. The China Medical Missionary Journal immediately replied that they were raising funds and making plans for a Chinese medical journal. Sadly, however, this Chinese journal never came into existence. In 1907, Dr. James B. Neal (1855-1925) of Tsinan (Jinan) mentioned that the Publication Committee recommend to the Association "it undertakes the publication of a standard series of text-books in Chinese, and when practicable a Chinese journal." 22 The same year, the Association was showing signs of change; the Chinese names of the Association and the Journal, publication of a Chinese textbook, as well as a Chinese journal were included on the agenda of discussion at the national conference of the Association. Except for the Chinese journal, all of the other planned activities seem to have come to fruition. However, progress on establishment of the Chinese medical journal ceased due to the poor health of Dr. Cousland himself.

Records show that in 1911 and 1912 the presidents of the Association all promised that a Chinese medical journal would be on the market very soon. This fact reflects the members' eagerness to see establishment of a Chinese version of the journal. Nevertheless, however enthusiastic and hopeful they were for publishing the journal, which they had planned for so long, it simply never materialized. Even in 1932, when the Chinese Medical Association merged with the National Medical Association of China, the China Medical Missionary Journal merged into the English section of the National Medical Journal of China to become the Chinese Medical Journal. No Chinese version was published.

\section{Chinese Doctors, Chinese Healing Arts, and Native Surgery}

Although the prospects for a Chinese version of the journal were bleak, the editors' desire to publish the China Medical Missionary Journal never waned. H. W. Boone established a goal for study of the Chinese perspective.

We want accurate reports of the Geology, Mineralogy, Flora and Fauna, and Food Supplies of every Province in the Empire; the Meteorology, the Physical geography, the prevailing diseases and the reasons for their

22 From the Publication Committee, $C M J, 1907 ; 21(2): 85$. 
prevalence. A collective investigation of diseases, mortality and of other matters. 23

He called such research "Chinatology." Before the China Medical Missionary Journal was published, the Imperial Maritime Medical Report was founded in 1871, which also attempted to define a similar scope for research. However, the Medical Report focused on the health and diseases of foreigners in China, as well as on some diseases in the Western medical world. Although the center of both studies was China, each had its respective concerns. The China Medical Missionary Journal defined its role as being "in the service of Chinese people," which makes the two journals complementary. Judging from what was published later, H. W. Boone's magnificent dream was never realized.

The China Medical Mission medical missionaries were always interested in Chinese medicine. With the large number of Chinese patients they saw, they were exposed firsthand to Chinese doctors. Moreover, since the medical missionaries met different people, they surely ended up seeing Chinese doctors at different levels. They basically all had negative opinions of Chinese doctors. This was especially true of J. G. Kerr, who lived and worked in Canton for over forty years and treated thousands of Chinese patients. Despite his long years in China, his bias against Chinese doctors was very strong. As he put it, Chinese doctors were synonymous with superstition and stupidity. As the chief editor of the China Medical Missionary Journal, his attitudes undoubtedly determined the future of medical journals in China. The China Medical Missionary Journal of 1894 published an article entitled "Medicine in China," written by Shanghai doctor Suvoong (Shu Gaodi), in which he found medicine as practiced by the Chinese "in a deplorable condition." Even Chinese doctors who spoke with erudition went to worship the mythical god Shen Nung(神农), who was said to have lived thousands of years earlier, or who might never have lived at all but in the imagination of later quidnuncs. ${ }^{24}$ On the other hand, Chinese doctors were not highly educated. They never read the compendium of medical herbs, but rather, only memorized some remedies passed down by their families or from ancient books. In the worst cases, they stole remedies and started their own businesses. The author also said that it was an unfortunate surprise that one of his friends from Shanghai did the same thing. 25

In another paper, "Native Treatment" (土医), published in the 1897 issue,

23 H. W. Boone, "The Medical Missionary Association of China: Its Future Work," CMMJ, 1887; 1(1): 4-5.

24 V. P. Suvoong, "Medicine in China," CMMJ, 1894; 8(4): 192.

25 V. P. Suvoong, "Medicine in China," CMMJ, 1894; 8(4): 192. 
H. A. Rangle gave examples of native treatment that Chinese doctors used. $\mathrm{He}$ had gone to a Chinese doctor once. The suggested cure was throwing into a fire a frog with an egg in its mouth, and then eating the egg after the fire had burnt to ashes. The author mocked this method by saying that frogs were too small to be powerful. They should've caught a tiger! ${ }^{26}$ The result of the conflict between the practices of Western medicine and Chinese medicine was that Western doctors became untrusting and contemptuous of Chinese cures and skills, and the way they were passed down. Hence, most early articles in the China Medical Missionary Journal about Chinese traditional medicine were written in a sarcastic and negative tone. In 1876, Kerr attended the International Medical Congress held in Philadelphia on behalf of Chinese medical missionaries. In a speech about medical missions, he described traditional Chinese medicine as lacking any scientific basis. ${ }^{27}$ In 1908, the China Medical Missionary Journal published an article called "Go Kan Ju Mu," which gave clear and detailed descriptions of a procedure that the author of the article had performed to rescue a woman who had cut out part of her liver to save her mother-in-law's life. The author admitted that the practices of Chinese people were more filial than Westerner's, but that children fulfilled their duty in a very superstitious way! This was precisely what Westerners could not understand. They were especially surprised that the patient learned such a method from books; how could Chinese books pass on such ignorant and superstitious practices?! 28

The Chinese Medical Missionary Journal aimed to be a professional science journal that reserved space for introducing traditional Chinese medicine and theory scientifically and objectively. A question raised by a reader was included in the first issue of 1887: "Does the Hanlin College at Peking still confer medical diplomas?" 29 The same question is raised in each "Notes and Queries" section. Dr. J. Thomson of Alice Memorial Hospital deemed that the Chinese term, Shen Fah (shoufa 手法), was a fair equivalent for the Western word, "surgery." Meanwhile, however, he also believed that Chinese used the term in a much more limited sense; in other words, it was used basically for only eight kinds of surgeries: palpation, reduction of fractures, reduction of dislocations, elevation of depressed bones, depression of elevations, shampooing, pushing outwards, grasping, and ten forms of surgical apparatus, which with the nine acupuncture needles form the surgeon's

26 H. A. Randle, "Native Treatment," CMMJ, 1897; 11(3-4): 214.

27 J. Kerr, "Medicine Missions at Home and Abroad," (A. L. Bancroft \& Company, Printers, San Francisco: 1878).

28 J. M. McCartney 割肝救母 “Go Kan Jiu Mu,” CMMJ, 1908; 22(3): 174-175.

29 "Notes and Queries," CMMJ, 1887; 1(1): 27. 
complete armamentarium. He named the above the Chinese "theory of surgery." He used two sources to gain knowledge of Chinese surgery: a book published in 1717 called the Golden Mirror of Eminent Medical Authors 医宗 金鉴), a classic of Chinese medicine, and through his own experience of working in a Hong Kong hospital, including his collection of medical articles and reports from other medical missionaries. ${ }^{30}$ However, based on his knowledge of Western surgery, he defined Chinese native surgery, including the Chinese movement cure, obstetrica, and inoculations, as well as surgery for syphilis, to be completely different from those classified in traditional Chinese medicine. But he believed it necessary to add Chinese native surgery as not an entirely uninteresting chapter to the history of the world's surgery, because "its importance lies in the fact that an intelligent knowledge of what has been and is, is a very essential qualification in those who would aid in establishing a new and better order of things." 31

Relatively speaking, Scottish physician John Dudgeon (1837-1902), who worked in Peking for nearly forty years, had a rather positive view of Chinese surgery. He translated and annotated part of the medical text by Chinese doctor Wang Ch'ing-jen (王清任 1768-1831) entitled I-lin-kai-tso (医林改错). $\mathrm{He}$ also claimed that Wang Ch'ing-jen was a modern Chinese anatomist. Moreover, Wang Ch'ing-jen and his I-lin-kai-tso became renowned in the Western world because of Dudgeon's translation. ${ }^{32}$ Like Thomas, Dudgeon chose to translate the osteology section of the Golden Mirror. He described ten ways to do surgery and their respective tools using both text and pictures. These ten ways included: kwo-shai (裹帘), chen-ting (振梃), pi-chien (披肩), suspension (攀索), three bricks (叠砖), communicating board (通木), loin pillars (腰柱), bamboo screen (竹帘), cedar fence (杉篱) and knee cap (抱膝). ${ }^{33}$ The China Medical Missionary Journal only translated two articles regarding this classic of traditional Chinese medicine. One article that represented study of Chinese surgical skill through practice was written by Joseph Edkins (18231905). He thought that the traditional fever curing method, nine knives (九针), had been forgotten by Chinese doctors. Chinese surgical doctors who hadn't learned anatomy and physiology were more like barbers. No one should be allowed to practice without a license, which would mean that they have no real acquaintance with medical science. ${ }^{34}$

30 John C. Thomson, "The History and Present Position of Chinese Native Surgery," CMMJ, 1893; 7 (1): 1-9.

31 Ibid., p. 8.

32 J. Dudgeon, “A Modern Chinese Anatomist," CMMJ, 1893; 7(4): 245-247; 1894; 8(1): 1-3.

33 J. Dudgeon, "A Chapter in Chinese Surgery," CMMJ, 1895; 9(2): 59-62.

34 J. Edkins, "Chinese Treatment of Fevers," CMMJ, 1895; 9(4): 228-231. 
In the twentieth century, the China Medical Missionary Journal's attitude towards Chinese medicine gradually grew more positive. The missionaries were capable of viewing Chinese therapies calmly and objectively. They introduced "treatment for mad dog bite" 35 through practice, personal experience, and European medical research. Western doctors realized that massage is an ancient Chinese way to cure disease and reduce sleeping problems. ${ }^{36}$ The author of the article on massage believed that it was the physician's or surgeon's prerogative, but naturally was one of the duties of the nurse.

When doctors from Shanghai were reporting methods of treating malignant diseases in the China Medical Missionary Journal, they mentioned curing with acupuncture as a method of Chinese surgeons. Furthermore, they proposed comparing Chinese medical methods in the various parts of the vast Chinese empire at some future date. ${ }^{37}$ The paper entitled, "Native Methods of Medical Practice in China," was published in the third issue of 1906. In the article, the author introduced Chinese customs regarding doctor visitations, methods of healing, the relationship between the physician and the patient, and the ethics of the Chinese medical profession. The chapter titles included: "How to Be a Physician in China," "How a Chinese Physician Treats His patients," "A Typical Chinese Prescription," "The Deadly Acupuncture Needle," as well as articles on Chinese festivals, etc. Considering the fact that Japan had accepted medical science sixty years earlier, he hoped that "Sixty years from now, if we do our duty, we shall look for the empirical practice in the Chinese empire." 38 In addition, the China Medical Missionary Journal started taking notice of the history of traditional Chinese medicine when the Association decided to disseminate Western medicine in China through the work of the missionaries. ${ }^{39}$

Investigating Chinese medicine could not have been accomplished without study of diseases in China. In fact, medical missionaries were more interested in Chinese diseases than in Chinese medicine. From their point of view, due to the vastness of the land and the density of the population, China was unequivocally a natural vessel for all kinds of diseases. Accordingly, the Association founded a Research Committee in 1907 that aimed to discover

35 “Treatment of Mad Dog Bite," CMMJ, 1906; 20(5): 209-211.

36 E. D. Vanderburgh, "Massage," CMMJ, 1907; 21(1): 60-63.

37 J. L. Maxwell, "The Operative Treatment of Malignant Disease in Mission Hospital," CMJ; 1909, 23(1): 9.

38 W. H. Jefferys, "'Freely Ye Have Received"”: Somewhat about Native Methods of Medical Practice in China and a Comparison", CMMJ; 1906, 20(3): $105-114$.

39 "From Our Chinese Medical Portfolio," CMMJ, 1906; 20(5): 206-208. Jos C. Thomson, "Native Practice and Practitioners," CMMJ, 1890; 4(4): 175. 
the nature of Chinese diseases. Through coordination with the Research Committee, the medical missionaries, who were dispersed throughout China, carried out investigations and research on parasitic diseases, which constituted the largest problem nationwide. In addition, regional diseases such as, typhus, leprosy, beriberi, and elephantiasis also became topics of research. In the twentieth century, papers regarding traditional Chinese hygiene gradually increased in number in the China Medical Missionary Journal.

Certainly, the negative impressions held by medical missionaries toward traditional Chinese medicine and the Chinese medical environment, about which there was no lack of wise criticism, inspired the missionaries to create a positive situation by spreading scientific medicine in China. The editor of the journal indicated that old native medical practices in China would atrophy and die, just as had happened in Japan. Yet there has never been made, so far as I know, a complete study of the old native practices with a view toward preserving its folklore, facts of historic interest, and ensuring that no practices of real value to scientific medicine have been overlooked. ${ }^{40}$

\section{Chinese Materia Medica}

Although the China Medical Missionary Journal was initially intended as a periodical for Chinese readers, it was read by foreign audiences for many years. The limited authority of the Association meant that the journal could only be published for readers inside the Association. Thus the content and the so-called Chinese "perspective" had to meet the requirements of foreign readers, most of whom were missionary doctors. This made Chinese herbal and medical research exceptionally critical because of the utility of its practical application to medical practice. One of the first questions asked by medical missionaries arriving in China was, "What reliable native drug can be obtained?" 41 Owing to the purpose of missions, missionaries chose to open dispensaries and hospitals far from urban areas, and especially from coastal cities. Since these locations were distant from ports, there were no Western pharmacies and it was extremely difficult to obtain Western medicine. Western doctors always had trouble conducting their work because of the lack of medicine. Kerr stated that study of Chinese materia medica "is one which should engage the attention of Members of the Association, and the opportunity now presents itself of initiating some by which united and systematic efforts may be made in this direction." 42

40 “Editorial, Native Methods of Medical Practice," CMMJ, 1906; 20(3): 139-140.

41 A. W. Douthwaite, "Notes on Chinese Materia Medica," CMMJ, 1888; 2(3): 119.

42 J. G. Kerr, “Chinese Materia Medica,” CMMJ, 1887; 1(1): 79. 
The China Medical Missionary Journal took the initiative in providing the missionaries in China with suitable drugs and instructions of use. Chinese pharmacopoeia was divided into three classes: those common to Chinese and Western medicine, such as rhubarb, camphor, opium, sulphate of soda, nitrate of potassium, liquorice, anise seed, cinnamon, musk, and asafetida; those that are inert, such as sulphate of lime, pearls, petrified crabs, deer-horns, ginseng, and numerous other articles; and those that are peculiar to Chinese medicine, and of which little or nothing was known. ${ }^{43}$ Kerr suggested focusing on investigation of the third class. The medical missionaries not only learned how these medications were used, but also their chemical compositions and the actual physiological reactions they induced during treatment. Finally, the chief editor recommended two books to the reader to aid in the study of Chinese medicine: The Pharmacopoeia of India and Dr. Porter Smith's Chinese Materia Medica, published by the Presbyterian Mission Press, Shanghai. This book provided an outline of the information contained in Chinese Herbs (Pun Tso or Pan Tsao 本草), which lists the properties and uses of Chinese medicine, as well as valuable facts about Chinese herbs collected from various sources. However, Dr. James B. Neal from Tungchowfu (Tongzhou fu 通州府) found that sixteen native drugs had not been mentioned in Dr. Smith's book. After Neal and his students independently analyzed their qualitative chemical compositions, Neal concluded that they were indeed native inorganic drugs. ${ }^{44}$

In regards to Chinese Herbs, foreign doctors admitted that it was one of the most popular works among the Chinese, and could not possibly be supplanted by the best Western publications for some generations to come. The wisest plan appeared to be to use it as a basis for introducing Western scientific research bearing on the subjects treated in the work. ${ }^{45}$ Chinese materia medica is composed of substances from the mineral, vegetable, and animal kingdoms. One medical missionary commented that identification of some of these important substances - very generally and largely used in China and neighboring countries - was "not yet satisfactory" 46 when the book was summarized in English and published in the Journal of the North-China Branch of the Royal Asiatic Society (Vol. XVI: 54). Critics thought cooperation with foreign medical practitioners was required to achieve best results. As every province of China had its own peculiar substances, names, and usages, medical missionaries could not achieve satisfactory results based on

43 Ibid.

44 J. B. Neal, "Sixteen Native Inorganic Drugs," CMMJ, 1888; 2(3): 116-118.

45 Ernst Faber, Dr. Theol, “A Revised Pen Ts'ao (本草)” CMMJ, 1890, 4(4): 270.

46 Ibid. p. 272. 
information from just one of a few localities along China's east coast. Medical missionaries suggested that the medicinal properties of each drug be listed according to the best Chinese authorities, but corrected and supplemented by Western science. Given that the different names might confuse Chinese readers, good drawings were needed, to which "the foreign scientific name should also be added." 47 Certainly, Chinese materia medica requires selection of prescriptions. Chinese native practitioners were accustomed to selecting appropriate prescriptions on their own.

Medicine and drugs have always been inseparable from the history of traditional Chinese medicine. In researching Chinese material medica, it was necessary to combine medicine with practice in treatment using traditional Chinese medicine. Study was an extension of practical use; foreign doctors were compelled to observe the actual effects of Chinese drugs and make objective evaluations of the results. With his fourteen years of experience as a doctor in the hinterland, Dr. Arthur W. Douthwaite (1848-1899) explained in his series of articles information concerning the character of native drugs and various methods of use by examining diseases and the effect of treatment. ${ }^{48} \mathrm{He}$ believed if others would join him in this task, they could accumulate a considerable amount of knowledge about Chinese materia medica, and thus greatly facilitate the operations of their successors. At the Association conference in 1890, Douthwaite read his paper, "The Use of Native Drugs by Medical Missionaries," 49 while Dr. Joseph C. Thomson of Macao read his paper entitled, "Chinese Materia Medica: Its Value to Medical Missionaries." 50

Cost was another reason that medical missionaries were drawn to Chinese materia medica. A simple and efficacious remedy long known and used by the Chinese came into favor in the West. Dr. George E. King administered ingluvin (a powder from the gizzard of a chicken) to his family and to Chinese patients. He found it to be a cheap, excellent substitute for pepsin, and could testify to its efficacy as an aid to digestion and appetite. ${ }^{51}$ The China Medical Missionary Journal also took the initiative in researching Chinese materia medica that year; a Committee of five was appointed to collect information on Chinese materia medica. The results of the investigations were subsequently published annually in the Journal. ${ }^{52}$

47 A. W. Douthwaite, "Notes on Chinese Materia Medica," CMMJ, 1888; 2(3): 119-120; (4): 164-165.

48 Ibid.

49 “Meetings of Members in Conference," CMMJ, 1890; 4(3): 100-104.

50 Ibid., pp. 115-119.

51 George King, "A Cheap Substitute for Pepsin," CMMJ, 1891; 5(1): 24.

52 "Meetings of Members in Conference," CMMJ, 1890; 4(3): 209. 
In 1893 the new president of the Association, Dr. W. Douthwaite, stated that the mission of the Association in China was to introduce modern science in place of superstition and magic and to sift through the Chinese materia medica to locate and test the therapeutic resources of the country. ${ }^{53}$ In 1907, Dr. William Wilson's work was referenced in a speech delivered by Douthwaite at the Association congress called "The Use of Native Drugs." The paper was a report on an exploratory study of Chinese materia medica based on Western scientific knowledge. ${ }^{54}$ Such research was further developed after the founding of the Research Committee. Studies on Chinese materia medica and the effects of native drugs can be found in the Research Committee reports of 1923, 1925, and 1926. The reports claimed that such native drugs could be used by Western doctors. Some of the reports even made clear that several native drugs had obvious effects on diseases and symptoms; the reports claimed that such new drugs would be valuable to developments in medical science.

Further, members of the Association published articles on studies of Chinese materia medica in European and American academic journals. Not a few medical missionaries devoted their academic careers to Chinese materia medica. The president of the Association, Dr. George A. Stuart, published a substantially revised version of F. Porter Smith's Chinese Materia Medica in 1911. Dr. Bernard E. Read of Peking Union Medical College was also interested in Chinese materia medica for many years and published a number of papers on this subject. He established protocol regarding laboratory inspection of native medicines, while drawing up a list of Chinese drugs of therapeutic interest to Western physicians. ${ }^{55} \mathrm{He}$ also investigated the trade in Chinese medicine in the markets of Jizhou, Hebei twice a year. He recommended his Western colleagues purchase native medicines from Chinese markets. ${ }^{56}$ In 1931, Dr. Read published his research on medicine derived from animals, an area that was definitely different from the ideas of the medical missionaries, who ignored the value of animal drugs in Chinese materia medica.57 Beginning in the twentieth century, investigation of Chinese

53 "Presidential Address," CMMJ, 1893; 7(1): 35-37.

54 William Wilson, "The Use of Native Drugs, with Illustrations," CMMJ, 1907; 20(3): 140 .

55 Bernard E. Read, "Chinese Drugs of Therapeutic Interest to Western Physicians," CMJ, 1923; 37(7): 589-591.

56 Bernard E. Read, Ph. C., M. S. Peking Union Medical College, Chinese Materia Medica: Vegetable Kingdom (by Frederick Porter Smith and George Author Stuart), CMJ, 1924; 38(8): 637-639.

57 James L. Maxwell, Chinese Materia Medica, Animal Drugs (by Bernard E. Read), CMJ, 1931; 45(12): 1204. 
materia medica became one of the most important subjects in Chinese medicine in modern science.

\section{Chinese Contributors: Termination of the China Medical Missionary Journal}

During its forty-five year history, the Chinese perspective in the China Medical Missionary Journal changed continually. Initially, it criticized as unscientific the theory and practice of traditional Chinese medicine in the name of science and mocked at the superstitious approach of Chinese to health. Its objective was to remove barriers to the medical mission rather than to propagate medical science. The views of the editors-in-chief obviously differed between Shanghai and Canton. ${ }^{58}$ Scientific periodicals were expected to be "informed critics" of science, supporting the value of science but wary of backing everything said in its name.

Any view of traditional Chinese medicine would be seriously incomplete without knowledge of Chinese culture and health customs, but transition in the attitudes of medical missionaries towards traditional Chinese medicine and Chinese materia medica was gradual. Scientific investigation and research on traditional Chinese medicine published in the Journal increasingly replaced the religious emphasis in the early years of the twentieth century. The transition was made complete in 1907 when the China Medical Missionary Journal became an actual medical journal. In 1914, when the National Medical Association of China was founded, Chinese contributors joined the research field, truly representing the "Chinese perspective." An irreversible and irredeemable transition took place when the China Medical Missionary Journal was merged into the English section of the National Medical Journal of China, resulting in termination of the former.

From the beginning of the twentieth century, the number of Chinese students educated by foreign doctors began increasing gradually. They either graduated from mission medical schools or received their educations abroad, and after returning to China, either started private businesses or took jobs at mission hospitals. Western-trained Chinese doctors became common. In 1905 three doctors of Chinese nationality became members of the Association. ${ }^{59}$ 1908 when the Executive Committee of the Association embarked on recruiting Chinese for membership in the Association, they emphasized that members must have graduated from some recognized medical college and

58 H. W. Boone, "The Medical Missionary Association of China: Its Future Work," CMMJ, 1887; 1(1): 1-5; J.G.K, Introductory, CMMJ, 1887; 1(1): 28-30.

59 CMMJ, 1905, 21(2): 38. 
engaged in medical missionary work in China. ${ }^{60}$ In the Association Triennial Conference of 1910, the president posed two issues to the entire membership. The first was: should medical men resident in China be admitted to active membership in the Association? The second was a proposition for expansion of membership by admitting Chinese graduates of medical schools in China, the difficulty of which would be assurance of sufficient qualifications. ${ }^{61}$ Dr. F. C. Yen (颜福庆, 1882-1970), a Chinese doctor who had graduated from Yale University, became the first active member in the Association through his participation in the 1910 conference. ${ }^{62}$

Dr. F. C. Yen's admission into the Association caused a quite a stir owing to his Chinese identity and the fact that he was simply a doctor rather than a missionary. Members of the Association were suspicious of Yen because he had the same access to excellence from the Association as did other members yet did not meet all of the Association's requirements. He was drawn to the missionary group due to his unique experiences and family background. Yen's grandfather, Wu Hongyu (吴虹玉), was the first and only Chinese contributor to the China Medical Missionary Journal before the twentieth century. $\mathrm{Wu}$ was also of the first generation of Chinese Christians to have studied Western medicine and was a close friend of Dr. Boone. Yen's uncle was the leader of the Chinese Christians in Shanghai and the co-founder of Shanghai St. John's University. The medical hospital of St. John's University was established at St. Luke's Hospital, which was founded by Dr. Wu. Dr. Yen had grown up around St. Luke's hospital and graduated from St. John's University. He was a Chinese student educated in the environment of medical missions. Dr. Yen went to America for further study in 1906, and became the first Asian student to earn a $\mathrm{PhD}$ in medicine at Yale University. After graduation from Yale medical school, Dr. Yen was employed as a member of the medical staff at the Hsiang-ya Medical College in Changsha. The hospital was administered by the Yale-in-China Mission. Yen established a good relationship with its president, Dr. Edward Hume (1876-1957), who was the most influential figure in the Association in the twentieth century. Dr. Yen published a "Customs Surgeon's Report on the Health of Changsha for the Six Months Ended 30th September" in two installments in the Chinese Medical Journal. This was the second article to be written by a Chinese for the Chinese Medical Journal, the first being by Yen's grandfather. ${ }^{63}$

60 "Chinese Membership in the Association," CMJ, 1908, 22(3): 191-192.

61 "President's Letter," CMJ, 1910; 24(2): 136.

$62 C M J, 1910,24(2): 120$. Dr. F. C. Yen was admitted to active membership in the Association.

63 F. C. Yen, “Customs Surgeon's Report on the Health of Changsha for the Six 
Another Chinese author for the Chinese Medical Journal before 1915 was Wu Lien-teh (伍连德, 1879-1960), a government official who was not connected with the mission society. Because of his successful leadership in the fight against plague in Manchuria in 1911, he not only was appointed to an important position by the Qing government, but also won respect from Western doctors both at home and abroad. Dr. Yen and Dr. Wu both appreciated Western medicine and the Western health system, and took the initiative to introduce Western medicine to China. Nevertheless, Dr. Wu was more focused on the study of traditional Chinese medicine and its history. In the papers he wrote for the Chinese Medical Journal he argued against the view of medical missionaries that there had been a lack of medical education or awareness of sanitation in Chinese medical history. Dr. Wu published two essays, "Memorandum on Medical Education in China" and "Awakening the Sanitary Conscience of China." 64 They were the first papers concerning Chinese medical history written by a Chinese contributor. Based on his research of the classics of traditional Chinese medicine, Dr. Wu argued that writings from as far back as the Zhou Dynasty 周代 (c. 1046-256BC) proved that a "sanitary conscience" had existed in China even at that time. China had built a system of professional physicians and Chinese had had very healthy habits and sanitary customs based on traditional medicine.

Dr. Yen's selfless national spirit was revealed in another way. In 1914, he suggested in the Church Yearbook that Chinese merge or cooperate with the mission medical colleges. ${ }^{65}$ His aim for the Chinese people was to have them take control of the development of Chinese new medicine. On the other hand, Dr. Yen emphasized to the foreign mission medical school in China that cooperation was the best way to overcome difficulties, citing as an example the cooperation with Chinese in medical education to establish the Hunan Yale Medical School. ${ }^{66} \mathrm{He}$ enumerated several advantages of such cooperation to the Mission Society in China and to the American Medical Association. 1) The good will of the Chinese would be enlisted by becoming partners,

Months Ended 30th September, 1911," CMJ, 1912; 26(5): 358-362; “Customs Surgeon's Report on the Health of Changsha for the Year ended 30th September, 1912," CMJ, 1913; 27(5): 397-400.

64 Wu Lien-teh, "Memorandum on Medical Education in China," CMJ, 1914; 27(1): 105-120; Wu Lien-teh, "Awakening the Sanitary Conscience of China," CMJ, 1915; 28(3): 222-229.

65 F. C. Yen, "Essays on Medicine," The Church Yearbook, 1914: 124.

66 F. C. Yen, "An Example of Cooperation with the Chinese in Medical Education," Journal of the American Medical Association, 1915; LXIV(17): 1385. Dr. Yen read this paper at the biennial convention of the China Medical Association, Shanghai on Feb. 151915. 
changing opposing forces into promoting ones. 2) Suspicion would be eliminated. Cooperation would bring closer touch with the Chinese and a truer understanding of the real purpose of missionaries in China, thus averting the besetting dread of the Chinese of foreign aggression in educational work. 3) The advice and practical aid of the Chinese workers would be indispensable in adapting such institutions to Chinese requirements. 4) Cooperation with the Chinese would give the work more permanency. In medical as in other lines, foreigners were merely laying foundations on which the Chinese themselves must build. By cooperation alone could the work be made continuous and lasting. Dr. Yen stated to the mission medical schools that cooperating with the Chinese people would push forward the development of medicine in China so that they could preserve their hundred years of hard work. Once the Chinese people had become predominant in medical education and hospital management, there would be no more opportunities for the missionaries.

As the main Chinese contributors to the China Medical Missionary Journal, both Dr. Yen and Dr. Wu gained respect from the Association. Dr. Yen and Dr. Wu kept their dignity in their cooperation with foreign doctors and the Association; they were neither humble nor pushy because they had both the independent spirit of Western medical science and the traditional spirit of Chinese intellectuals. More importantly, they did not simply express their wishes and thoughts to the journals; rather, they took action. In February 1915, they proposed the establishment of a Chinese doctors' organization, later known as the National Medical Association of China (NMAC). Dr. Yen was the first chairman and Dr. Wu was secretary. When the association was founded a year later, Dr. Wu became the first congressman. Although by that time the China Medical Missionary Journal had already lowered the bar to allow participation by Chinese, the habitual contemptuousness and superiority displayed by Western doctors towards Chinese doctors had apparently enraged the latter. After all, not all Chinese doctors were respected by the Association in the same way as Dr. Yen and Dr. Wu were. Hence, to some extent, the National Medical Association of China was established as a counterforce to the Medical Missionary Association of China. ${ }^{67}$ The association was a medical community created by Chinese doctors who practiced Western medicine. Their aim was to conduct research on Chinese Western medical science and public health in an effort to facilitate conversations with the Association on an equal basis. In December 1915, Dr. Wu announced in the Chinese Medical Journal that the National Medical

67 Dr. Wu and Dr. Yen suggested establishing the National Medical Association of China at the conference held by the Medical Missionary Association of China in 1915. CMJ, 1916; 30(2): 111. 
Association of China had been founded. ${ }^{68}$ In the Declaration of the NMAC, Dr. Yen claimed that the association would facilitate association between foreigners and Chinese in order to "keep pace with the Medical Association in Europe and America." 69 The National Medical Association of China established its own journal called the National Medical Journal of China. It was a periodical published in both English and Chinese, the English content being abstracts of the Chinese articles, some of which were from the Chinese Medical Journal. Subsequently, the Chinese Medical Journal and National Medical Journal of China shared the same readers and contributors. In the 1920s, articles by Chinese doctors appeared frequently in the Chinese Medical Journal. In the 1930s, the Medical Missionary Association of China had to consider merging permanently with the National Medical Association of China. The merger took place in 1932. The Chinese Medical Journal merged with the National Medical Journal of China to become a new medical periodical renamed the Chinese Medical Journal. It consisted of two periodicals, one in Chinese and the other in English. The Chinese Medical Journal remained the English Chinese Medical Journal. The old popular sections on developments in surgical science and modern medicine, the hotly discussed studies of clinical medicine and Chinese medical education that had been carried in the Chinese Medical Journal were kept. The editor of the Chinese Medical Journal' believed that the merger of the two journals would make for a brighter future. ${ }^{70}$

\section{Conclusion}

Ultimately, the initial desire of the editors of the China Medical Missionary Journal to create a Chinese medical journal did not come to fruition even after it merged into the Chinese Medical Journal. Medical missionaries were more than just Western doctors; they were the only group of people that had access to every level of Chinese society. They had more interaction with Chinese patients and dealt most closely with local diseases, hence they sincerely cared for their patients. The Chinese perspective was essentially one of the most important academic sections of the China Medical Missionary Journal owing to its coverage of Chinese medicine and the path it created to facilitate Chinese medicine. The default Chinese perspective continues in the English version of the Chinese Medical Journal even today. The focus,

68 "The Honorary Secretary," The National Medical Association of China, CMJ, 1915, 28(6): 407-408.

69 F. C. Yen, "The Declaration of the National Medical Association of China," The National Medical Journal of China (NMJC). 1915; 1(1): 52.

70 "The Journal," CMJ, 1932, 46(1): 87. 
however, has shifted from the study and introduction of traditional Chinese medicine to demonstrating to the world the results of the study of Chinese medical science. This is still a masterpiece in the Chinese medical profession. Its mission to spread Western medicine has now been taken over by the Chinese version of the Chinese Medical Journal. ${ }^{71}$

What the Executive of the Medical Missionary Association of China and the Board of the Yale-in-China Mission could not have foreseen was that their choice to cooperate with the Chinese people resulted in the redundancy of their organizations. This is the story, however, of how Chinese medicine took its place in modern history. Initially non-participants in the medical associations run by Westerners in their country, Chinese eventually took the lead in disseminating medicine to their own people; they started by cooperating and ended up creating their own history. The establishment and termination of the Medical Missionary Association of China and the China Medical Missionary Journal' were turning points in this period of history. The Chinese perspective spearheaded by the Medical Missionary Association of China created paths and opportunities for traditional Chinese medicine to reach out to the world. Their pioneering experimental studies laid a solid foundation for Chinese scholars to study Chinese medicine scientifically, and offered methodology and technology for reference. The influence of the Medical Missionary Association of China and the China Medical Missionary Journal on China's new medicine and the birth of Chinese scientific medicine cannot be overestimated. This is precisely why the China Medical Missionary Journal became the most enduring periodical in modern Chinese history, whereas the medical missions themselves died out over time. The Chinese perspective concerning Chinese medical history, Chinese medical practice, Chinese medical classics, as well as Chinese materia medica constituted the core spirit and vitalized the China Medical Missionary Journal. But as Dr. Yen said in 1915, "Only a Chinese can fully understand the Chinese point of view."72

71 "The New Life of Our Journal," CMJ, 1932; 18(1): 186.

72 F. C. Yen, "An Example of Cooperation with the Chinese in Medical Education," Journal of the American Medical Association, 1915; LXIV(17): 1385. 